Check for updates

Cite this: RSC Adv., 2017, 7, 46208

\title{
Integrated production of furfural and levulinic acid from corncob in a one-pot batch reaction incorporating distillation using step temperature profiling $\dagger$
}

\begin{abstract}
Hairui Ji, ${ }^{a}$ J. Y. Zhu (D) ${ }^{* b}$ and Roland Gleisner ${ }^{\mathrm{b}}$
Furfural and levulinic acid (LA) are potential major renewable platform chemicals for producing biochemicals and biofuels. In this study, integrated conversion of corncob to furfural and LA was carried out in a one-pot system using $p$-toluenesulfonic acid $(p-\mathrm{TsOH})$ and step temperature profiling. A batch reaction incorporating distillation (BRD) resulted in a good furfural production yield of $61.6 \%$ based on the corncob xylan content for the hydrolysis conditions tested. Distillation not only reduced furfural loss due to side reactions to humins, but also resulted in a fairly pure and concentrated furfural solution. At the end of the first distillation step, the reaction temperature was increased to convert hexoses into LA with a maximal production yield of $61.3 \pm 7.8 \%$ based on corncob glucan content. LA was extracted with good yield as LA-ester using low-cost alcohols and then phase separated to recycle alcohols and $p$ $\mathrm{TsOH}$. Good recyclability and reusability of $p-\mathrm{TsOH}$ and alcohols were demonstrated.
\end{abstract}

Received 9th August 2017

Accepted 25th September 2017

DOI: $10.1039 / c 7 r a 08818 c$

rsc.li/rsc-advances reduce humins formation by transferring furfural into the organic phase. ${ }^{10}$ Using a large amount of organic solution is of course not suitable for commercial furfural production. Twostage processes were also employed. ${ }^{10-12}$ These processes hydrolyze pentosans to monomeric pentoses, with subsequent acid-catalyzed dehydration into furfural. The additional stage will inevitably increase furfural production cost. The second stage can be eliminated when using batch production together with immediate separation of furfural after formation. Furfural yield in excess of $85 \%$ theoretical was achieved by condensing the vapor fraction from the reactor. ${ }^{13}$ This approach not only improved furfural yield by protecting furfural from degradation, but also facilitated furfural recovery by avoiding costly distillation from a dilute solution to obtain a highly concentrated furfural condensate.

Many researchers have used one-pot catalytic conversion of cellulose and lignocellulosic biomass to LA. ${ }^{\mathbf{1 4 - 1 7}}$ Catalysts can improve LA yield from lignocellulosic biomass. However, the one-pot processes cannot avoid parasitic pathway reactions from furfural, glucose, and HMF to humins, ${ }^{18}$ in addition to the inefficient utilization of hemicelluloses. Two-stage acidcatalyzed conversion of lignocelluloses into LA was developed to address this problem. ${ }^{\mathbf{1} 19}$ Pentose was extracted in the first stage prior to LA production, which may improve LA yield. However, the additional stage increases the cost of LA production. Another study reported the production of furfural along with HMF in the first stage using a plug-flow reactor followed by continued degradation of glucose and intermediates to produce fed.us

$\dagger$ Electronic supplementary information (ESI) available. See DOI:

10.1039/c7ra08818c

${ }^{a}$ College of Printing and Packaging, Qilu University of Technology, Jinan 250353, China

${ }^{b} U S D A$ 
LA in the second stage using a stirred-tank reactor. ${ }^{\mathbf{2 0 2 1}}$ This process used two reactors, which increases the capital cost.

Separation of LA through distillation is difficult due to its high boiling point of $245{ }^{\circ} \mathrm{C}$, which hinders the commercialization of LA production from lignocelluloses. Gurbuz et al. developed a biphasic reactor with alkylphenol solvents to selectively partition LA from acidic aqueous solutions. ${ }^{22}$ Li et al. reported that high yields of LA ester can be obtained directly from aqueous hydrolysis mixtures by using toluene and water as co-solvents with the addition of isopropanol. ${ }^{23}$ The high cost and toxicity of these solvents were challenges for commercial applications.

Here we report integrated production of furfural and LA through acid catalytic conversion of corncob in a one-pot system using a two-step temperature profile as shown in Fig. 1. Furfural was separated with high concentration and purity through steam stripping during the low temperature step. LA was produced during the high temperature step and separated as LA-ester from acidic aqueous solutions by a novel extraction method, using low-cost and non-toxic solvents, which has not been reported in literature. The solvents and acid solution can be reused. Therefore, this study has practical significance to conversion of lignocellulosic biomass to platform chemicals and biofuels.

\section{Results and discussion}

\section{Effect of furfural on LA production from a glucose solution}

As described above, the effects of furfural and HMF on LA production were first evaluated using a glucose solution spiked with furfural and HMF in batch reactions. Glucose degradation was enhanced with the application of furfural (Fig. 2A). The terminal glucose concentration was $5.75 \mathrm{~g} \mathrm{~L}^{-1}$ with the application of furfural compared with $6.80 \mathrm{~g} \mathrm{~L}^{-1}$ without furfural at 60 min. Formic acid (FA) formation was reduced with the application of furfural (Fig. 2A). Furfural degradation was substantial as shown in Fig. 2B. HMF concentration in the liquor increased initially due to formation from glucose and then decreased with reaction time as a result of degradation to LA (Fig. 2C). The application of furfural reduced HMF concentration. The maximal HMF concentration was $0.58 \mathrm{~g} \mathrm{~L}^{-1}$ and occurred at $20 \mathrm{~min}$ into the reaction without the application of furfural compared with $0.53 \mathrm{~g} \mathrm{~L}^{-1}$ with furfural. This decrease can be attributed to the side reaction between furfural and intermediates. ${ }^{\mathbf{2 4 , 2 5}}$ The application of furfural reduced terminal LA production from 8.76 to $7.27 \mathrm{~g} \mathrm{~L}^{-1}$ at $120 \mathrm{~min}$. Simultaneous production of furfural and LA was accompanied by parasitic pathway reactions between furfural and either glucose, furfural or HMF, forming black resinous polymeric products, or humins. ${ }^{18,26}$ The formation of humins was due to degradation of furfural and HMF through aldol addition followed by condensation or polymerization with itself or other reaction intermediates. $^{\mathbf{2 4 2 5}}$ Therefore, separating furfural from the process stream, such as using distillation in this study, can improve the LA production.

\section{Batch reaction temperature on furfural and LA yield from corncob}

To study the effect of reaction temperature on furfural and LA production, batch experiments without steam stripping were conducted in a temperature range between 110 and $190{ }^{\circ} \mathrm{C}$. Furfural production was improved when the reaction temperature was increased from $100{ }^{\circ} \mathrm{C}$ to $130{ }^{\circ} \mathrm{C}$ and decreased with
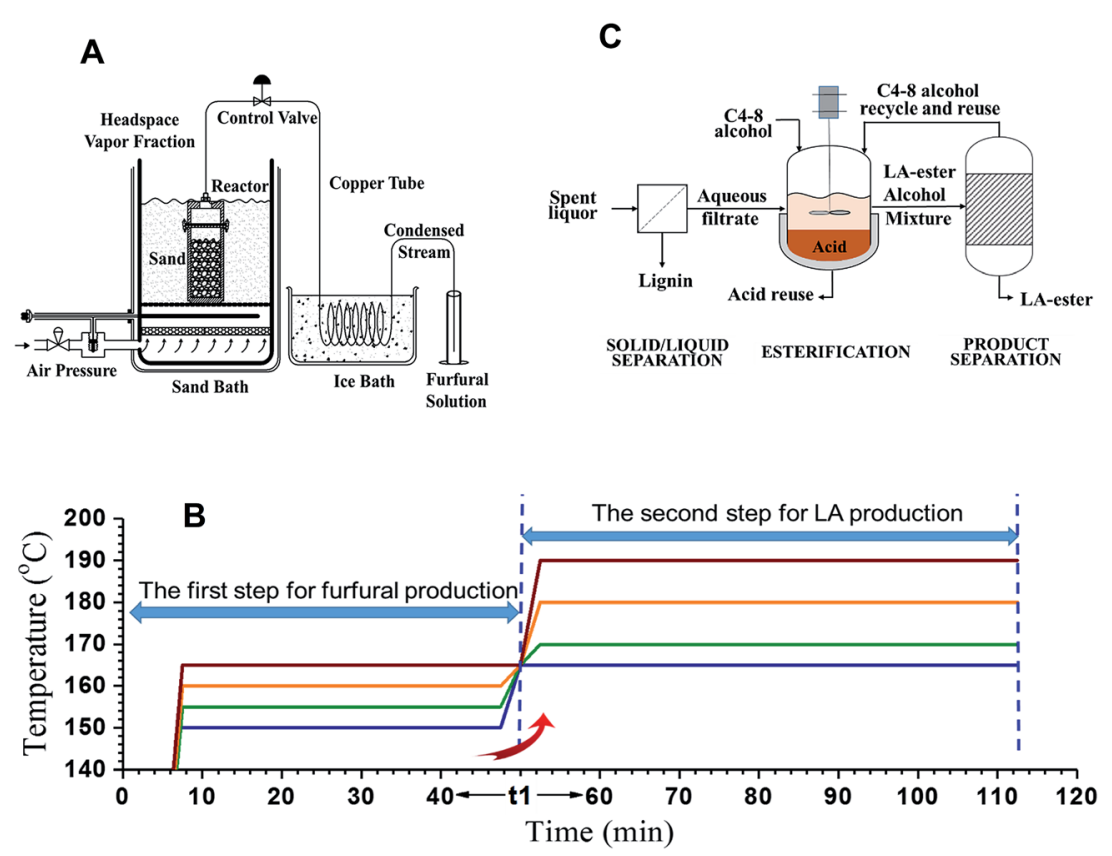

Fig. 1 Schematic diagrams showing the productions of furfural and LA using two step temperature profile and separations. (A) Dehydration experimental apparatus; (B) two-step temperature profiles; (C) LA separation process flow schematics. 


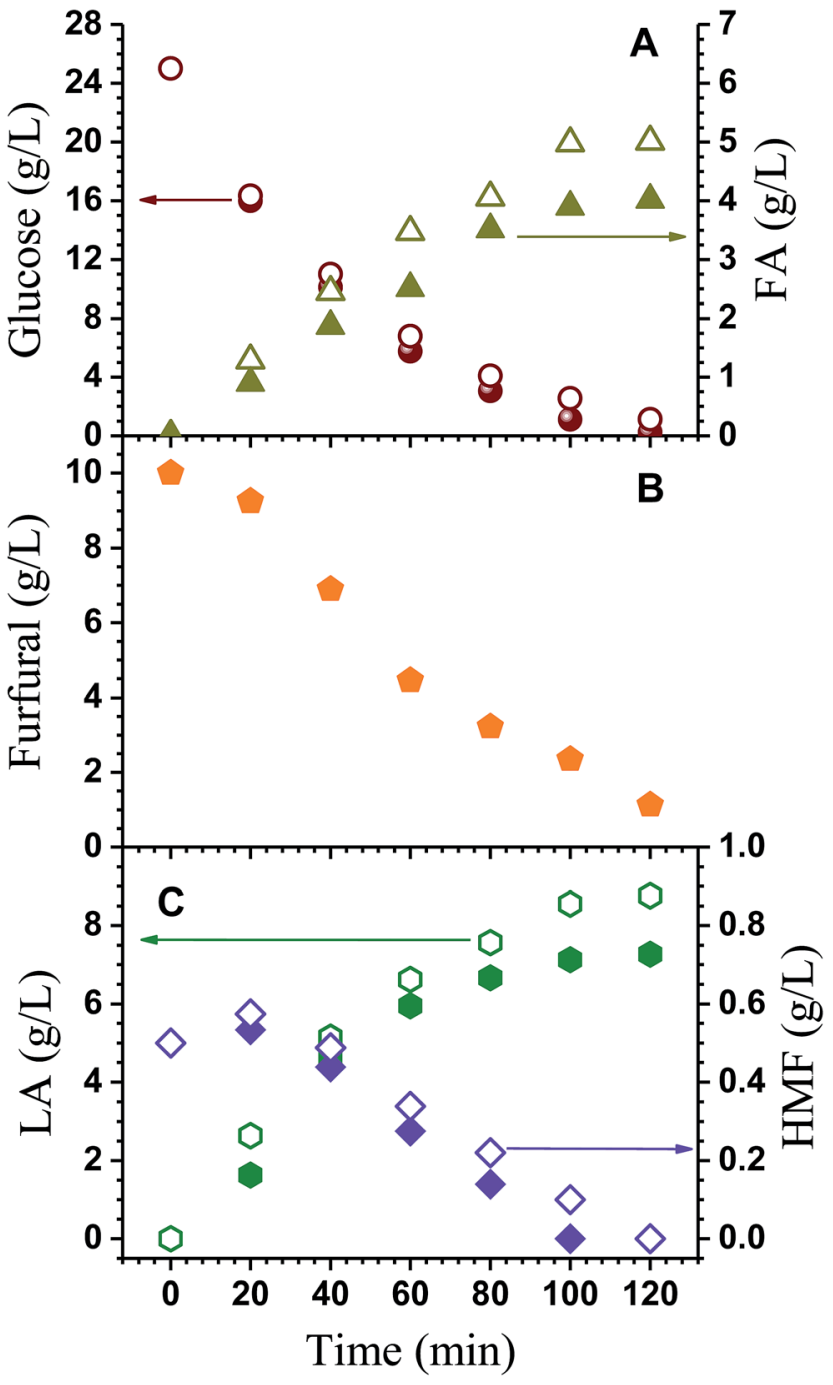

Fig. 2 Effect of furfural and HMF on time-dependent LA production from a glucose solution of $25 \mathrm{~g} \mathrm{~L}^{-1}$ spiked with furfural of $10 \mathrm{~g} \mathrm{~L}^{-1}$ and HMF of $0.5 \mathrm{~g} \mathrm{~L}^{-1}$ using $p-\mathrm{TsOH}$ of $1.1 \mathrm{~mol} \mathrm{~L}^{-1}$ at $150{ }^{\circ} \mathrm{C}$. Solid symbols: with furfural and HMF; open symbols: without furfural and HMF as control.

further increases in temperature as shown in Fig. 3. A similar trend was also observed for LA but with peak yield at $180{ }^{\circ} \mathrm{C}$. HMF is the main conversion intermediate from glucose to LA and can be rapidly converted to LA using acid. This can be seen from the low HMF concentration in the reaction mixture (Fig. 3). The results shown in Fig. 3 clearly indicate that furfural and LA yields are highly dependent on reaction temperature. The fact that maximal furfural yield was obtained at a relatively lower $T$ of $130{ }^{\circ} \mathrm{C}$ while the maximal yield of LA was achieved at a higher $T$ of $180{ }^{\circ} \mathrm{C}$, suggests a two-step temperature profile scheme can be employed to achieve production of furfural and LA in a one-pot system, as will be discussed below.

\section{Furfural and LA production from corncob via steam stripping experiments}

In a previous study, ${ }^{27}$ we reported the optimization of furfural production from corncob through steam stripping experiments

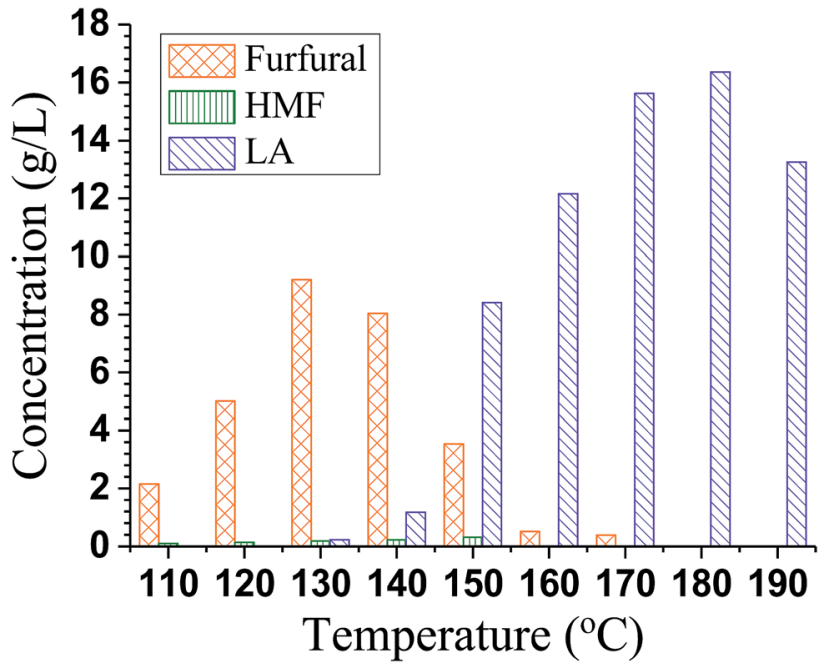

Fig. 3 Effect of reaction temperature on yield of furfural and LA in batch experiments with reaction time of $70 \mathrm{~min}$ and catalyst $p-\mathrm{TsOH}$ concentration of $=1.1 \mathrm{~mol} \mathrm{~L}^{-1}$

using a reaction kinetics based severity, namely the combined hydrolysis factor (CHF) ${ }^{28}$ Optimal furfural yield can be achieved in a CHF range of 830-1850. Here we extended the previous study to include efficient hexose conversion to LA for a corncob biorefinery operation. A CHF of 2200 was chosen in designing the first-step furfural production in the present study, which is higher than the upper range of CHF of 1850 for optimal furfural production. This is in consideration of our previous study ${ }^{27}$ that indicated a higher severity can increase HMF production for maximizing LA yield. The elevated $\mathrm{CHF}$ did reduce furfural yields approximately $10 \%$ compared with the optimal $70 \%$ theoretical furfural yields reported previously at a $\mathrm{CHF}$ of approximately 1600 using the same $p$-TsOH concentration and similar temperatures but with longer reaction times. In the present study, four schemes for first-step furfural production were used as listed in Table 1 followed by the variation of reaction temperature in the second-step to maximize LA yield.

In Scheme A, glucose yield from cellulose reached $39.7 \%$ theoretical yield at the end of step 1 (or $t_{1}=60 \mathrm{~min}$ ) as shown Fig. 4A. The reaction was continued in step 2 where $T_{2}$ was ramped to a constant value ranging between 165 and $190{ }^{\circ} \mathrm{C}$. A total of four different runs were carried out. $T_{2}$ had a significant effect on LA production. The LA yield improved with increasing $T_{2}$ and time in the range studied. Peak LA yield was occurred at $T_{2}=190{ }^{\circ} \mathrm{C}$ in approximately $120 \mathrm{~min}$ (or $t_{2}=60 \mathrm{~min}$ ) into the reaction. This suggests a high $T_{2}$ of $190{ }^{\circ} \mathrm{C}$ may be necessary to overcome the activation energy of the reaction ${ }^{29}$ to maximize LA production. Similarly, using Scheme B for step 1, peak LA yield was achieved at $T_{2}=190{ }^{\circ} \mathrm{C}$ in $t_{2}=60 \mathrm{~min}$ in step 2 , as shown Fig. 4B. A higher LA peak yield of $64.6 \%$ was achieved compared to $61.0 \%$ using Scheme A. An even higher LA peak yield of $67.2 \%$ was achieved using Scheme $\mathrm{C}$ at $T_{2}=180{ }^{\circ} \mathrm{C}$ for $t_{2}=40 \mathrm{~min}$. The highest LA peak yield of $71.8 \%$ was achieved using Scheme D at $T_{2}=170{ }^{\circ} \mathrm{C}$ for $t_{2}=40 \mathrm{~min}$ among all four schemes evaluated for step 1 . 
Table 1 Furfural yield at similar CHF of approximately 2220

\begin{tabular}{lllllllll}
\hline Scheme & $\begin{array}{l}p \text {-TsOH } \\
\left(\mathrm{mol} \mathrm{L}^{-1}\right)\end{array}$ & $T_{1}\left({ }^{\circ} \mathrm{C}\right)$ & $\begin{array}{l}\text { Time }\left(t_{1}\right) \\
(\mathrm{min})\end{array}$ & $\begin{array}{l}\mathrm{CHF} \\
(\mathrm{min} \mathrm{mol} \mathrm{L})\end{array}$ & $\begin{array}{l}\text { Residual } \\
\text { xylose }(\%)\end{array}$ & $\begin{array}{l}\text { Glucose yield } \\
(\%)\end{array}$ & $\begin{array}{l}\text { Furfural concentration } \\
\left(\mathrm{g} \mathrm{L}^{-1}\right)\end{array}$ & $\begin{array}{l}\text { Furfural production } \\
\text { yield }(\%)\end{array}$ \\
\hline A & 0.28 & 165 & 60 & 2287 & 2.52 & 39.67 & 20.45 & 55.06 \\
B & 0.57 & 160 & 40 & 2189 & 3.19 & 36.31 & 22.15 & 59.63 \\
C & 0.87 & 155 & 40 & 2337 & 1.70 & 38.73 & 19.74 & 53.13 \\
D & 1.18 & 150 & 40 & 2198 & 0.26 & 36.06 & 22.88 & 61.60
\end{tabular}

Several observations can be made from the results shown in Fig. 4A-D: (1) for all the schemes for step 1, the production yield of furfural almost reached a maximum value; (2) the maximal LA yield from each scheme was the peak yield obtained at the highest $T_{2}$ for step 2; (3) the maximal LA yield of $71.8 \%$, from all the 16 runs and among all schemes, was achieved at the highest $T_{2}\left(170{ }^{\circ} \mathrm{C}\right)$ under Scheme $\mathrm{D}$ that had the highest $p$-TsOH catalyst concentration. These observations indicate a high $T_{2}$ may be necessary to overcome activation energy for the reaction to form LA. A longer reaction time may also help to improve LA yield. The activation energy for the conversion of intermediates, such as glucose and furan to humins, is reported to be the highest among all the kinetics of conversion; ${ }^{18,30-32}$ LA degradation to humins, therefore, becomes important only after LA reached maximum. Future studies using higher temperature $T_{2}$ or longer $t_{2}$ are needed to verify this argument. It appears that a high catalyst concentration and low temperature such as Scheme D may be beneficial to improve LA yield. A lower severity, i.e., $\mathrm{CHF}<1600$, in step 1 can be used to improve furfural yield as furfural yield was decreased at higher CHF as listed in Table 1.

Table 2 shows the comparison of furfural and LA yield between the conventional dehydration process carried out in two steps without steam stripping in a batch reactor (BR) and the two-step process in batch reactor with distillation (BRD) under the exact same reaction conditions, i.e., at $p$-TsOH $1.18 \mathrm{~mol} \mathrm{~L}^{-1}$ and $150{ }^{\circ} \mathrm{C}$ for $40 \mathrm{~min}$ for the step 1 and at $170{ }^{\circ} \mathrm{C}$ for $40 \mathrm{~min}$ for the step 2 (Scheme $\mathrm{D}$ at $T_{2}=170{ }^{\circ} \mathrm{C}$ ). LA yield using BRD was $61.3 \pm 7.8 \%$, greater than that using BR of $52.4 \%$. Distillation in BRD substantially improved furfural yield to $67.1 \pm 4.3 \%$ from $2.6 \%$ using $\mathrm{BR}$ without distillation. Furthermore, BRD recovered most furfural through distillation, i.e., distillation efficiency of $74.2 \%$ (Table 3 , fresh run), or a total recovered furfural yield of approximately $50 \%$ without optimization. Batch distillation also resulted in a relatively pure furfural as well as pure LA solution as shown from chromatographic analysis (Fig. S1 and $\mathrm{S} 2, \uparrow$ respectively).

\section{Extraction of LA and reusability of $p$-TsOH}

LA extraction efficiency from the spent liquor, obtained from Scheme D at $T_{2}=170{ }^{\circ} \mathrm{C}$, were compared using different alcohols such as isobutanol, 1-pentanol, 1-octanol. The benefits of LA extraction using these alcohols are high extraction efficiency and the recyclability of acid and alcohols. As described in Fig. 1C, the spent liquor was mixed with an alcohol. The LA in the liquor was then transferred to an alcohol phase as a soluble
LA-ester (upper tank). The results in Table 3 (labelled as fresh) indicated that isobutanol produced the highest LA extraction efficiency of $78.2 \%$ (based on the amount of LA produced), followed by 1-pentanol at $77.8 \pm 4.2 \%$, while 1-octanol resulted in the lowest extraction efficiency of $75.5 \pm 1.9 \%$.

The water soluble $p$-TsOH was phase separated from the alcohol-ester solution and subsequently reused for three times to evaluate its efficacy for LA production. The results using 1pentanol and 1-octanol as extraction solvents are listed in Table 3. Efficiencies of furfural distillation (60.4\%) and LA extraction (56.2\%) decreased substantially for the third reuse of $p$-TsOH and pentanol-ester solution, perhaps due to the slight solubility of 1-pentanol in water. Using 1-octanol, a water-insoluble solvent, eliminated the problem associated with low furfural recovery. Distillation efficiency of furfural was maintained near $80 \%$, while both LA production yield and LA extraction efficiency remained lower in the recycling runs than those from using fresh chemicals. Higher concentration of $p$-TsOH contributed to higher LA production yield with same reaction severity (Fig. 4D) as discussed early. The slight loss of $p$-TsOH may have contributed into LA production loss. Saturation in alcohol extraction of LA may resulted in efficiency loss in extraction.

The advantages of the present process is that esterification and separation of the ester from the aqueous reaction mixture are combined in a single reactive extraction step without the need for additional solvents. The water-immiscible alcohol that acts as an esterifying agent also serves as the solvent for the extraction of LA ester. Since most of the furfural has been distilled off in the step 1, the formation of undesired, tar-like furfural by-products is minimized in the acid reaction mixture. Therefore, the aqueous mixture does not need to be treated before recycling. Furthermore, the reactive extraction strategy can be carried out directly for the aqueous reaction mixture from acid hydrolysis of biomass without the need to remove the acid catalyst. The same acid catalyst used in acid hydrolysis for the production of LA can be used for esterification between LA and $\mathrm{C} 4-\mathrm{C} 8$ alcohol in the reactive extraction process. The aqueous phase in bottom of the tank (Fig. 2C) can be recycled for reuse.

\section{Conclusions}

Integrated conversion of corncob to furfural and LA in a one-pot system was developed using a batch reactor with distillation and a two-step temperature profile. The vapor fraction from the 

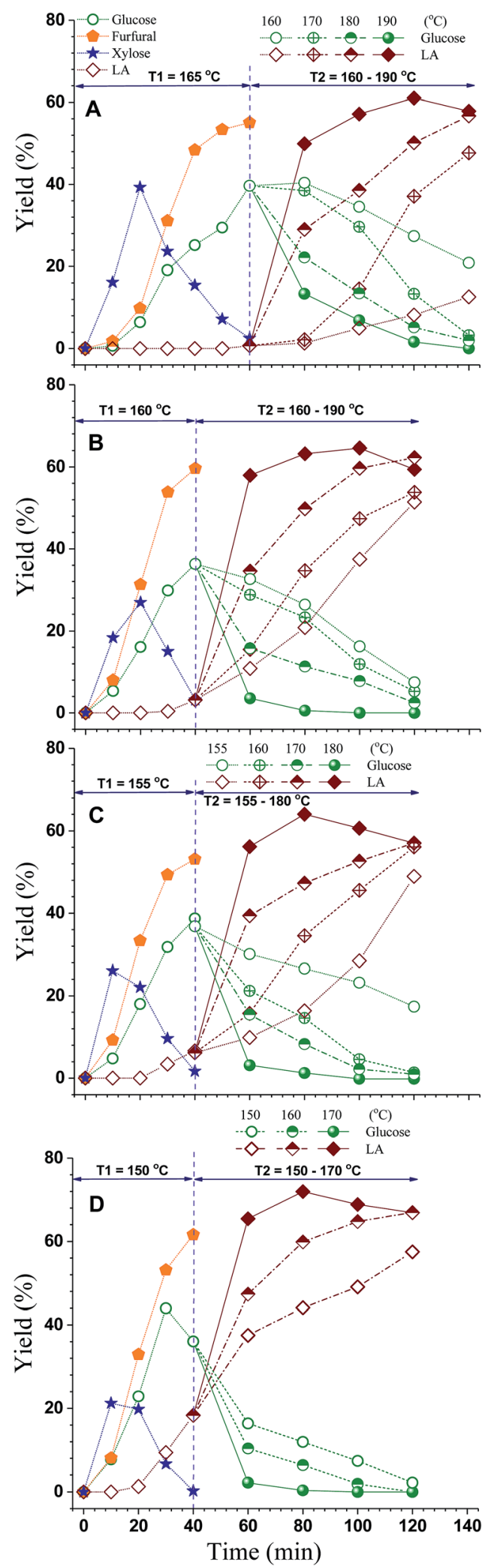

Fig. 4 Effect of step 2 temperature on LA production under four step 1 furfural production conditions of similar CHF approximately 2200 as listed in Table 1.
Table 2 Comparisons of furfural and LA production yields between BR and BRD. Reaction condition: $p-\mathrm{TsOH}=1.18 \mathrm{~mol} \mathrm{~L}-1$ at $150{ }^{\circ} \mathrm{C}$ for $40 \mathrm{~min}$ in the first step, and at $170^{\circ} \mathrm{C}$ for $40 \mathrm{~min}$ in the second step

\begin{tabular}{lll}
\hline & Furfural (\%) & LA (\%) \\
\hline BR & 2.6 & 52.4 \\
BRD & $67.1 \pm 4.3$ & $61.3 \pm 7.8$
\end{tabular}

Table 3 Comparisons of recovery yields of furfural and LA using isobutanol, 1-pentanol, 1-octanol extraction and evaluation of the reusability and efficacy of $p-\mathrm{TsOH}$ and the three alcohols for furfural and LA production and recovery

\begin{tabular}{|c|c|c|c|c|}
\hline Run no. & $\begin{array}{l}\text { Furfural } \\
\text { production } \\
\text { yield (\%) }\end{array}$ & $\begin{array}{l}\text { Furfural } \\
\text { distillation } \\
\text { efficiency (\%) }\end{array}$ & $\begin{array}{l}\text { LA production } \\
\text { yield }(\%)\end{array}$ & $\begin{array}{l}\text { LA extraction } \\
\text { efficiency (\%) }\end{array}$ \\
\hline \multicolumn{5}{|c|}{ 1-Pentanol $\left(\mathrm{C}_{5} \mathrm{H}_{10} \mathrm{OH}\right)$} \\
\hline Fresh & $67.1 \pm 4.3$ & $74.2 \pm 1.3$ & $61.3 \pm 7.8$ & $77.8 \pm 4.2$ \\
\hline 1 & 63.4 & 74.8 & 43.4 & 67.8 \\
\hline 2 & 48.1 & 67.4 & 38.4 & 62.6 \\
\hline 3 & 45.2 & 60.4 & 43.3 & 56.2 \\
\hline \multicolumn{5}{|c|}{ Isobutanol $\left(\mathrm{C}_{4} \mathrm{H}_{8} \mathrm{OH}\right)$} \\
\hline Fresh & $67.1 \pm 4.3$ & $74.2 \pm 1.3$ & $61.3 \pm 7.8$ & 78.2 \\
\hline \multicolumn{5}{|c|}{ 1-Octanol $\left(\mathrm{C}_{8} \mathrm{H}_{16} \mathrm{OH}\right)$} \\
\hline Fresh & $67.1 \pm 4.3$ & $74.2 \pm 1.3$ & $61.3 \pm 7.8$ & $75.5 \pm 1.9$ \\
\hline 1 & 64.0 & 77.3 & 47.2 & 66.1 \\
\hline 2 & 66.1 & 77.0 & 46.6 & 64.0 \\
\hline 3 & 62.1 & 78.2 & 52.2 & 50.0 \\
\hline
\end{tabular}

reactor was condensed to produce furfural with a production yield of $61.6 \%$ of the theoretical yield based on total xylan in the system at the start of the reaction. The distillation of furfural also substantially improved LA production yield as compared to processing without distillation under the same conditions. The maximum LA yield $(61.3 \pm 7.8 \%)$ was obtained. Furthermore, phase separation of LA using organic solvent was effective in terms of production yield and recyclability.

\section{Materials and methods}

\section{Materials}

Corncob used in this study was kindly provided by Dr Xuejun Pan of University of Wisconsin-Madison. Corncob was Wileymilled into particles of 20-40 mesh (model no. 2, Arthur Thomas Co, Philadelphia, PA, USA). $p$-Toluenesulfonic acid ( $p$ TsOH), LA, HMF and calcium carbonate were ACS reagent grade and purchased from Sigma-Aldrich (St. Louis, MO, USA).

\section{Batch experiments using glucose solutions}

To study the effects of HMF and furfural on LA production, $50 \mathrm{~mL}$ aqueous glucose solution at $25 \mathrm{~g} \mathrm{~L}^{-1}$ spiked with $\mathrm{HMF}$ at $0.5 \mathrm{~g} \mathrm{~L}^{-1}$ and furfural at $10 \mathrm{~g} \mathrm{~L}^{-1}$ was dehydrated at $150{ }^{\circ} \mathrm{C}$ in a $100 \mathrm{~mL}$ stainless steel reactor using $p$-TsOH as catalyst at $1.1 \mathrm{~mol} \mathrm{~L}^{-1}$. 


\section{Batch hydrolysis and dehydration of corncob}

Ground corncob of $6 \mathrm{~g}$ in oven dry (OD) weight was mixed with $50 \mathrm{~mL} p$-TsOH solution of $1.1 \mathrm{~mol} \mathrm{~L}^{-1}$ in a $100 \mathrm{~mL}$ stainless steel reactor. Batch reactions, without steam stripping of furfural, were conducted in a temperature range $110-190{ }^{\circ} \mathrm{C}$ with a $10{ }^{\circ} \mathrm{C}$ increment to investigate the effect of reaction temperature on furfural and LA production from corncob.

\section{One-pot furfural and LA production and separation}

Reaction experiments with steam stripping of furfural were conducted in a laboratory apparatus designed to simulate conditions in a batch reactive distillation process as described previously. ${ }^{27}$ A $100 \mathrm{~mL}$ stainless steel reactor was fitted with a valve that can be opened to continuously remove a portion of vapor from the reactor headspace as schematically shown in Fig. 1A. Copper tubing was immersed in an ice bath to condense the vapor extracted from the reactor headspace. The reactor was filled with $80 \mathrm{~mL}$ of $p$-TsOH solution at a given concentration $\left(0.28,0.57,0.87,1.18 \mathrm{~mol} \mathrm{~L}^{-1}\right)$ and $6 \mathrm{~g}$ in oven dry (OD) weight ground corncob. The reactor was heated to a specified temperature using a sand bath (Techne F932D, Techne Inc., USA). The reactions in the first step for furfural production were performed at $150{ }^{\circ} \mathrm{C}$ for $t_{1}=60 \mathrm{~min}$, or at 155,160 and $165^{\circ} \mathrm{C}$ for $t_{1}=40 \mathrm{~min}$ (Fig. 1B). The vapor extraction valve was slightly open after the reactor reached the desired temperature. Heat was continuously supplied to the reactor to offset the cooling effect due to vapor loss to maintain a nearly constant temperature throughout the reaction. For each experiment, a total of $30 \mathrm{~mL}$ of furfural solution was extracted from the reactor into a beaker resulted in a concentrated $p$-TsOH solution of approximately $0.45,0.93,1.44,1.98 \mathrm{~mol} \mathrm{~L}^{-1}$ for step 1 Scheme A to $\mathrm{D}$, respectively. When the reaction time reached the preset 40 or $60 \mathrm{~min}$, temperature was raised to $150,155,160,170,180$, or $190{ }^{\circ} \mathrm{C}$ in less than $5 \mathrm{~min}$ and maintained for $t_{2}=60 \mathrm{~min}$ in the second step reaction for LA production (Fig. 1B). At the end of each reaction, the reactor was cooled down using tap water before opening. Water insoluble solids (WIS) and freely drainable spent liquor were separated with a Büchner funnel using filter paper (15 cm, slow, Fisher Scientific Inc., Pittsburgh, PA, USA). The collected spent liquor and distilled furfural solution were analyzed by HPLC.

An organic solvent (either C4, C5, or C8 alcohol), having the same volume as the collected spent liquor from filtration, was added into the spent liquor. The mixture was then heated to $90{ }^{\circ} \mathrm{C}$ for $3 \mathrm{~h}$ to form LA-esters which is soluble in the alcohol used. Hence, LA was then separated as LA-ester from the aqueous $p$-TsOH solution using a phase separation funnel. The remaining acid solution was reused again. The $\mathrm{C} 4-8$ alcohol can then be separated using a rotary evaporator or $\mathrm{CO}_{2}$ extraction.

\section{Analytical methods}

All solid samples were hydrolyzed using sulfuric acid in two steps for carbohydrate analyses by the Analytical Chemistry and Microscopy Lab (ACML) at the Forest Products Lab as described previously. ${ }^{33}$ Monosaccharides, LA, furfural, HMF, acetic acid, formic acid in the pretreatment spent liquors, and distilled furfural solutions were determined using a Dionex HPLC system (Ultimate 3000, Thermo Scientific) equipped with an RI (RI-101) detector and a UV detector (VWD-3400RS), as described previously. ${ }^{34}$

\section{Determining furfural and LA production yields and recovery efficiencies}

Furfural production yields were determined from the distillate at the end of each step 1 reaction and from the spent liquor at the end of the step 2 reaction. The steam stripping efficiency of furfural was the percentage of furfural distillated as the total amount of furfural measured for the run. LA production yields were calculated using the LA measured from the spent liquor at the end of each step 2 reaction. LA extraction efficiency was define as the ratio of reduced and total LA in spent liquor. The reported yields of furfural and LA were all in percent of theoretical based on xylan and glucan content in the corncob.

\section{Conflicts of interest}

The authors have no conflict of interest.

\section{Acknowledgements}

This work was partially supported by the Chinese Scholarship Council (CSC). The funding from the programs made the visiting appointment of Ji at the USDA Forest Products Laboratory (FPL) possible. We would like to acknowledge Fred Matt of US Forest Service Forest Products Laboratory for conducting carbohydrate analyses.

\section{References}

1 T. Runge and C. H. Zhang, Ind. Eng. Chem. Res., 2012, 51, 3265-3270.

2 R. Weingarten, W. C. Conner and G. W. Huber, Energy Environ. Sci., 2012, 5, 7559.

3 J. J. Bozell, L. Moens, D. C. Elliott, Y. Wang, G. G. Neuenscwander, S. W. Fitzpatrick, R. J. Bilski and J. L. Jarnefeld, Resour., Conserv. Recycl., 2000, 28, 227-239.

4 R. Mariscal, P. Maireles-Torres, M. Ojeda, I. Sádaba and M. López Granados, Energy Environ. Sci., 2016, 9, 1144-1189. 5 K. Yan, Y. Yang, J. Chai and Y. Lu, Appl. Catal., B, 2015, 179, 292-304.

6 A. Bohre, S. Dutta, B. Saha and M. M. Abu-Omar, ACS Sustainable Chem. Eng., 2015, 3, 1263-1277.

7 G. W. Huber, S. Iborra and A. Corma, Chem. Rev., 2006, 106, 4044-4098.

8 J. P. Lange, E. van der Heide, J. van Buijtenen and R. Price, ChemSusChem, 2012, 5, 150-166.

9 K. Yan and A. Chen, Fuel, 2014, 115, 101-108.

10 R. Weingarten, J. Cho, W. C. Conner and G. W. Huber, Green Chem., 2010, 12, 1423-1429.

11 A. J. Deng, J. L. Ren, H. L. Li, F. Peng and R. C. Sun, RSC Adv., 2015, 5, 60264-60272. 
12 F. Lopez, M. T. Garcia, M. J. Feria, J. C. Garcia, C. M. de Diego, M. A. M. Zamudio and M. J. Diaz, Chem. Eng. J., 2014, 240, 195-201.

13 A. Mandalika and T. Runge, Green Chem., 2012, 14, 31753184.

14 N. Ya'aini, N. A. S. Amin and M. Asmadi, Bioresour. Technol., 2012, 116, 58-65.

15 N. A. S. Ramli and N. A. S. Amin, Energy Convers. Manage., 2015, 95, 10-19.

16 G. T. Jeong, Ind. Crops Prod., 2014, 62, 77-83.

17 M. Kang, S. W. Kim, J. W. Kim, T. H. Kim and J. S. Kim, Renew. Energ., 2013, 54, 173-179.

18 K. Dussan, B. Girisuta, D. Haverty, J. J. Leahy and M. H. Hayes, Bioresour. Technol., 2013, 149, 216-224.

19 Z. G. Yang, H. Y. Kang, Y. F. Guo, G. Q. Zhuang, Z. H. Bai, H. X. Zhang, C. X. Feng and Y. P. Dong, Ind. Crops Prod., 2013, 46, 205-209.

20 S. F. D. J. Hayes, M. H. B. Hayes and J. R. H. Ross, in Biorefineries-Industry Processes and Products, Wiley-VCH, Verlag GmbH, 2005, pp. 139-164.

$21 \mathrm{~W}$. F. Stephen, in Feedstocks for the Future, American Chemical Society, 2006, pp. 271-287.

22 E. I. Gurbuz, S. G. Wettstein and J. A. Dumesic, ChemSusChem, 2012, 5, 383-387.
23 C. R. Li, D. Q. Ding, Q. N. Xia, X. H. Liu and Y. Q. Wang, ChemSusChem, 2016, 9, 1712-1718.

24 J. Lewkowski, ARKIVOC, 2001, 17-54.

25 S. K. R. Patil and C. R. F. Lund, Energy Fuels, 2011, 25, 47454755.

26 R. Weingarten, W. C. Conner and G. W. Huber, Energy Environ. Sci., 2012, 5, 7559-7574.

27 H. Ji, L. Chen, J. Y. Zhu, R. Gleisner and X. Zhang, Ind. Eng. Chem. Res., 2016, 55, 11253-11259.

28 W. Zhu, C. J. Houtman, J. Y. Zhu, R. Gleisner and K. F. Chen, Process Biochem., 2012, 47, 785-791.

29 Y. Chen, G. Li, F. Yang and S. M. Zhang, Polym. Degrad. Stab., 2011, 96, 863-869.

30 C. Chang, X. J. Ma and P. L. Cen, Chin. J. Chem. Eng., 2009, 17, 835-839.

31 B. Girisuta, K. Dussan, D. Haverty, J. J. Leahy and M. H. B. Hayes, Chem. Eng. J., 2013, 217, 61-70.

32 B. Girisuta, L. P. B. M. Janssen and H. J. Heeres, Ind. Eng. Chem. Res., 2007, 46, 1696-1708.

33 X. Luo, R. Gleisner, S. Tian, J. Negron, W. Zhu, E. Horn, X. J. Pan and J. Y. Zhu, Ind. Eng. Chem. Res., 2010, 49, 8258-8266.

34 J. Y. Zhu, M. S. Chandra, F. Gu, R. Gleisner, R. Reiner, J. Sessions, G. Marrs, J. Gao and D. Anderson, Bioresour. Technol., 2015, 179, 390-397. 